\title{
Studi Kasus Pengaruh Penggunaan Bahasa Jawa dalam Kegiatan Pembelajaran Mata Pelajaran Bahasa Indonesia di Kalangan Siswa SMP Muhammadiyah 8 Surakarta
}

\author{
Shindy Tresna Vinansih ${ }^{1 *}$, Hesti Ratnasari ${ }^{2)}$, Istanto ${ }^{3)}$ \\ 1,2,3) Universitas Muhammadiyah Surakarta \\ *a310170092@student.ums.ac.id
}

\begin{abstract}
Abstrak: Bagi sebagian besar penutur bahasa Indonesia, bahasa daerah merupakan bahasa ibu atau bahasa pertama dalam kehidupan sehari-hari. Hal ini mengakibatkan pengaruh pada saat mereka menggunakan bahasa Indonesia. Hal ini pula dapat dijumpai di SMP Muhammadiyah 8 Surakarta. Mayoritas siswa di sekolah tersebut adalah penutur bahasa Jawa. Kebiasaan menggunakan bahasa Jawa tersebut membuat siswa sering kali menggunakan bahasa daerah yakni, bahasa Jawa dalam proses pembelajaran, khususnya ketika kegiatan pembelajaran mata pelajaran bahasa Indonesia. Penulisan artikel ini bertujuan untuk mengetahui sejauh mana pengaruh bahasa ibu terhadap bahasa Indonesia dalam mata pelajaran Bahasa Indonesia khususnya di sekolah tersebut serta memberi pemahaman serta kesadaran pentingnya penggunaan bahasa Indonesia. Artikel ini ditulis berdasarkan hasil observasi langsung yang dilaksanakan dalam kurun waktu 2 minggu serta bersumber dari beberapa referensi seperti jurnal,buku dan lain sebagainya. Keterbiasaan menggunakan bahasa jawa dalam kehidupan sehari-hari, tentunya menimbulkan dampak positif maupun dampak negatif. Namun, guru sendiri harus mempunya cara agar siswanya mampu secara konsisten dan tepat dalam menggunakan bahasa Indonesia. Oleh karena itu, penguasaan kedua bahasa tersebut seharusnya bisa diseimbangkan, agar kelak anak mampu menjadi seseorang yang dapat berbahasa Indonesia yang baik dan benar. Untuk merealisasikan keseimbangan itu maka ada beberapa cara yang dapat dilakukan.
\end{abstract}

Kata kunci: Pengaruh, Bahasa Jawa, Bahasa Indonesia, kegiatan pembelajaran, mata pelajaran bahasa Indonesia.

\section{PENDAHULUAN}

Sejak ditetapkannya dalam Undang-Undang Dasar RI 1945 sebagai bahasa resmi kenegaraan, penggunaan bahasa Indonesia kian meluas, dapat dikatakan sudah mencakup wilayah Negara Republik Indonesia, meskipun menurut sensus penduduk 1980, yang dapat berbahasa Indonesia baru $61,4 \%$, dan yang sehari-hari berbahasa Indonesia baru $12 \%$. Bandingkan yang berbahasa Jawa ada $40 \%$, dan berbahasa Sunda 15\%.

Penggunaan bahasa Indonesia dilakukan oleh orang-orang yang berlatar belakang bahasa daerah yang berbeda- beda, menjadikan bahasa Indonesia sangat bervariasi dan beragam-ragam. Hal ini karena bahasa Indonesia itu saling memengaruhi dengan bahasabahasa daerah setempat. Akibatnya kita bisa mengatakan adanya bahasa Indonesia ragam Jawa Barat, yang sangat kesunda-sundaan, ada bahasa Indonesia kejawa- jawaan, ada bahasa Indonesia yang 
kebatak-batakan dan sebagainya (Abdul Chaer, Leonie Agustina, 2010: 227).

Bahasa adalah sistem lambang bunyi yang arbitrer yang digunakan oleh para anggota kelompok sosial untuk bekerja sama, berkomunikasi dan mengidentifikasi diri (Kridalaksana.2001). Bahasa Indonesia sendiri dijadikan sebagai lingua franca dari beratus-ratus bahasa daerah yang ada di Indonesia. Dikutip dari Wikipedia (Diakses pada tanggal 5-Februari-2019) Lingau franca sendiri merupakan sebuah istilah linguistik yang artinya adalah "bahasa pengantar" atau "bahasa pergaulan" di suatu tempat di mana terdapat penutur bahasa yang berbeda-beda. Bagi sebagian besar penutur bahasa Indonesia, bahasa daerah merupakan bahasa ibu atau bahasa pertama dalam kehidupan sehari-hari. Hal ini mengakibatkan pengaruh pada saat mereka menggunakan bahasa Indonesia. Sebagai contoh penelitian Kholidah (2015) yang menemukan interaksi siswa dan guru dalam pembelajaran dengan menggunakan bahasa Jawa. Pemakaian bahasa Jawa tidak lagi bersifat monolingual, tetapi cenderung multilingal.

Penulisan artikel ini didasarkan pada temuan penulis melaksanakan observasi selama 2 minggu di SMP Muhammadiyah 8 Surakarta yang terletak di Jl. Sri Kuncoro. No. 12 Danukusuman, Serengan, Kota Surakarta. Di mana mayoritas siswa di sekolah tersebut adalah penutur bahasa Jawa. Karena hal tersebut siswa sering kali menggunakan bahasa daerah yakni, bahasa Jawa dalam proses pembelajaran, khususnya ketika kegiatan pembelajaran mata pelajaran bahasa Indonesia. Siswa seringkali memahami kesulitan ketika dihadapi suatu keadaan di mana mereka diharuskan menggunakan bahasa Indonesia baku.

Kedwibahasaan dapat terjadi pada setiap masyarakat yang mengenal dua bahasa, hal ini lah yang terjadi di kalangan siswa sekolah tersebut. Chaer (2003: 65), menyatakan bahwa bilingualis atau kedwibahasaan sebagai akibat dari kontak bahasa, terlihat seperti kasus yang muncul dalam pemakaian bahasa seperti campur kode. Hal ini sejalan dengan penelitian Mulyani (2014) yang menemukan interferensi leksikal bentuk dasar bahasa Jawa dalam pembelajaran bahasa Indonesia siswa kelas XI SMA N Tuban. Interferensi sendiri merupakan penyimpangan norma-norma bahasa yang terjadi dalam tuturan dwibahasawan sebagai akibat pengenalan lebih dar satu bahasa. Pengaruh kedwibahasaan siswa XI SMA N Tuban tersebut yaitu masih mengalami kesulitan dalam mencari sinonim bahasa Indonesia.

Diharapkan dengan adanya penulisan artikel ini dapat memberi pemahaman serta kesadaran mengenai pentingnya bahasa Indonesia dalam proses pembelajaran. Sebab bahasa Indonesia sendiri adalah bahasa resmi yang digunakan untuk menyatukan berbagai perbedaan bahasa yang ada agar satu sama lain dapat saling berinteraksi dengan 
baik. Selain itu, penulisan artikel ini juga mengharapkan agar siswa mampu dan berminat mempelajari bahasa Indonesia sebagai bekal untuk kehidupan dikemudian hari.

Artikel ini bertujuan untuk mengetahui sejauh mana pengaruh penggunaan bahasa Jawa ketika pembelajaran mata pelajaran Bahasa Indonesia, di SMP Muhammadiyah 8 Surakarta. Serta untuk memberi pemahaman serta kesadaran mengenai pentingnya bahasa Indonesia dalam proses pembelajaran. Selain itu, penulisan artikel ini juga mengharapkan agar siswa mampu dan berminat mempelajari bahasa Indonesia sebagai bekal untuk kehidupan dikemudian hari.

\section{METODE}

Penulisan artikel ini menggunakan metode Library Research, Obeservasi langsung dan Deskriftif kualitatif. Di mana metode Library Research ini adalah metode dengan mengumpulkan data-data dari buku, artikel-artikel serta website di internet. Metode Observasi langsung dilaksanakan di SMP Muhammadiyah 8 Surakarta Jln. Sri Kuncoro No.12, Danu Kusuman, Serengan, Kota Surakarta, Jawa Tengah. Yang dilaksanakan dalam kurun waktu 2 minggu. Pembuatan artikel ini membutuhkan waktu 1 minggu. Sedangkan dikutip dari salah satu web, Penelitian deskriptif kualitatif merupakan salah satu dari jenis penelitian yang termasuk dalam jenis penelitian kualitatif. Adapun tujuan dari penelitian ini adalah untuk mengungkapkan kejadian atau fakta, keadaan, fenomena, variabel dan keadaan yang terjadi saat penelitian berlangsung dengan menyuguhkan apa yang sebenarnya terjadi. Penelitian ini menafsirkan dan menguraikan data yang bersangkutan dengan situasi yang sedang terjadi, sikap serta pandangan yang terjadi di dalam suatu masyarakat, pertentangan antara dua keadaan atau lebih, hubungan antar variable yang timbul, perbedaan antar fakta yang ada serta pengaruhnya terhadap suatu kondisi, dan sebagainya. (Lingustik.id. 2016: Diakses Pada 12-Februari-2019)

\section{HASIL DAN PEMBAHASAN}

Berdasarkan hasil observasi yang dilakukan penulis di SMP Muhammadiyah 8 Surakarta, ditemukan fakta bahwa 95\% dari jumlah keseluruhan siswanya adalah penutur bahasa Jawa. Mayoritas ini lah yang menyebabkan hampir seluruh siswanya menggunakan bahasa jawa saat jam pelajaran bahasa Indonesia berlangsung. Selain disebabkan oleh hampir seluruh siswanya adalah penutur Jawa, Hal ini terjadi karena tidak adanya kesepakatan antara guru dengan siswa perihal penggunaan bahasa dalam keberlangsungan pembelajaran di kelas (Dini Rahma Septiana.2014: Diakses pada tanggal 8- Februari2019). Ini dapat dibuktikan dengan banyaknya siswa yang bertanya mengenai salah satu materi pembelajaran bahasa indonesia dengan menggunakan bahasa Jawa atau meskipun mereka bertanya 
menggunakan bahasa Indonesia, tetapi tetap saja terjadi campur kode di dalam ujarannya. Campur kode adalah pencampuran dua (lebih) bahasa atau ragam bahasa dalam satu tindak bahasa tanpa ada sesuatu dalam situasi berbahasa itu yang menuntut percampuran bahasa" (Nababan. 1989: 28).

Meskipun siswanya bertanya menggunakan bahasa Jawa, guru bahasa Indonesia di SMP Muhahammadiyah 8 Surakarta berusaha untuk tetap memberi penjelasan mengenai materi tersebut menggunakan bahasa Indonesia meski terkadang terpaksa mengunakan bahasa Jawa. Kejadian tersebut dapat diketahui melalui hasil pengamatan penulis dibeberapa kelas seperti kelas 7A,7B,7C dan $8 \mathrm{C}$.

Contoh kasus lain adalah ketika guru pelajaran bahasa Indonesia meminta siswanya untuk menceritakan kembali dari cerita yang telah dibacanya, beberapa siswa justru bertanya kepada penulis,selaku orang yang saat itu sedang mengamati kegiatan pembelajaran dan berada di dekatnya. Beberapa siswa tersebut bertanya apakah boleh menceritakan cerita yang telah dibacanya menggunakan bahasa jawa, padahal saat itu tengah berlangsung kegiatan pembelajaran bahasa Indonesia.

Selain itu, pengaruh bahasa Jawa juga membuat siswa kesulitan untuk memahami materi pelajaran bahasa Indonesia yang ada dalam buku pegangan siswa. Seperti materi mengenai karakteristik tokoh dari sebuah fabel. Siswa tidak dapat memahami beberapa kata dalam bahasa Indonesia seperti kata 'tapir', 'mutiara', serta 'kuda berbulu harimau' sehingga guru harus menerangkan makna dari kata-kata tersebut menggunakan bahasa Jawa, hal ini bertujuan agar para siswanya dapat secara mudah memahami materi tersebut.

Dari penjelasan di atas dapat disimpulkan bahwa pengaruh bahasa Jawa pada pembelajaran disebabkan oleh beberapa faktor. Diantaranya adalah pertama, mayoritas penggunaan bahasa daerah adalah dilingkungan pedesaan, disitulah bahasa daerah (bahasa Jawa) lebih dominan dibandingkan bahasa indonesia. Kedua, bahasa yang diperoleh siswa dari orangtua atau pengasuh sejak lahir adalah bahasa Jawa sehingga bahasa Jawa itulah yang menjadi bahasa ibu penutur tersebut. Sejalan dengan pernyataan tersebut dapat menyebabkan siswa menjadi terbiasa dalam penggunaan bahasa Jawa sehingga siswa akan mengalami kesulitan ketika diminta untuk berbahasa Indonesia yang baik. Faktor lain yang mempengaruhi pemakaian bahasa Jawa antara guru dan siswa seperti temuan Rulyandi, et.al (2014) yakni terdiri atas; (a) faktor kebiasaan guru dan siswa menggunakan bahasa Jawa, (b) pengaruh bahasa Ibu siswa, dan (c) penggunaan alih kode dan campur kode merupakan strategi komunikasi guru agar materi pelajaran dapat dipahami dengan baik 
oleh siswa.

Pengaruh bahasa Jawa dalam kegiatan pembelajaran khususunya mata pelajaran bahasa Indonesia, menimbulkan beberapa dampak, diantaranya:

1. Pengaruh Positif

a. Siswa dapat berperan sebagai pelestari budaya lewat bahasa Jawa yang digunakannya dalam kehidupan sehari-hari

b. Siswa lebih cepat memahami materi pelajaran ketika berinteraksi dengan bahasa Jawa

c. Menimbulkan keakraban dalam interaksi di dalam kelas

2. Pengaruh Negatif

a. Siswa menjadi kurang paham dalam menggunakanbahasa Indonesia yang baik dan benar

b. Siswa mengalami kesulitan ketika dihadapi situasi yang mengharuskannya berbahasa Indonesia

c. Siswa terbiasa menggunakan bahasa Jawa hingga terkadang lupa beberapa kosa kata dalam bahasa Indonesia.

Beberapa dampak di atas senada dengan penelitian Widianto (2015) menemukan penggunaan bahasa Jawa memunculkan dua kemungkinan yaitu integrasi dan pergeseran bahasa. Kemungkinan yang berbahaya adalah terjadinya pergeseran bahasa pada sistem atau kata tertentu. Pergeseran bahasa tersebut terjadi pada bahasa Indonesia yang digunakan oleh masyarakat pondok pesantren. Apabila kosakata yang mendapatkan interferensi itu digunakan secara bersama-sama dan terus menerus dalam waktu yang cukup lama, interferensi menjadi gejala pergeseran bahasa pada kosakata tertentu di kalangan masyarakat pondok pesantren. Dalam hal ini, interferensi mengarah pada "kekacauan" bahasa.

Untuk mengatasi keterbiasaan penggunaan bahasa Jawa dalam kegiatan pembelajaran, guru pihak sekolah menyiasati dengan mengadakan lomba-lomba yang mengharuskan menggunakan bahasa Indonesia seperti lomba pidato, lomba membaca cerita dalam bahasa Indonesia. Selain itu, untuk tetap menjaga kelestarian ciri khas dari para penutur Jawa, sekolah juga mengadakan lomba bercerita dengan menggunakan Bahasa Jawa. Jadi, sekolah pada dasarnya sudah berusaha untuk mampu menyeimbangkan kedua penggunaan bahasa tersebut. Namun, mayoritas siswa ketika berada di luar sekolah terbiasa menggunakan bahasa Jawa. Hal tersebut yang menjadi salah satu alasan mengapa banyak siswa yang terpengaruh oleh penggunaan bahasa Jawa. Senada dengan Triyanto, et.al (2016) bahwa faktor yang menyebabkan terjadinya interferensi morfologi dan sintaksis bahasa Jawa ke dalam bahasa Indonesia yaitu faktor linguistik dan faktor nonlinguistik. Faktor linguistik meliputi (1) penguasaan bahasa Jawa sebagai bahasa pertama, (2) rendahnya pengu-asaan bahasa Indonesia sebagai bahasa target, dan (3) kedwibahasaan peserta didik. Faktor nonlinguistik meliputi (1) kebiasaan, (2) lingkungan, (3) sikap bahasa, 
(4) motivasi belajar bahasa Indonesia, (5) guru sebagai pelaksana pembelajaran, dan (6) faktor evaluasi pembelajaran.

Sejalan dengan penelitian Hidayat, et.al (2015) yang menemukan pengaruh bahasa jawa dalam bahasa Indonesia pada keterampilan berbicara siswa kelas XI SMA N 1 Pleret, Bantul. Pengaruh tersebut berupa pertama, interferensi fonologi terjadi karena terdapat prenasalisasi berupa suara hidung yang mendahului fonem $/ \mathrm{b} /, / \mathrm{d} / \mathrm{l} / \mathrm{j} /$, dan /g/. Kedua, interferensi morfologi, terjadi karena terdapat afiksasi yang dipengaruhi sistem afiksasi bahasa Jawa, yaitu (a) prefiks $n-, k e^{-}$, $n y, n g-, m$ - (b) sufiks -e, (c) konfiks ke - an yang mengacu ke - en, dan (d) penggunaan akhiran -nya yang merujuk pada panambang -e. Ketiga, interferensi leksikal terjadi karena terdapat penggunaan leksikal pada dan tak yang merupakan leksikal bahasa Jawa. interferensi fonologi terjadi karena terdapat prenasalisasi berupa suara hidung yang mendahului fonem $/ \mathrm{b} /, / \mathrm{d} /, / \mathrm{j} /$, dan $/ \mathrm{g} /$. Adapun, faktor nonlinguistik yang mempengaruhi dalam penggunaan bahasa Jawa yaitu kebiasaan, dominasi penguasaan bahasa Jawa, dan sikab berbahasa.

Penulis menyarakankan di SMP Muhammadiyah 8 Surakarta diadakan budaya literasi membaca sebelum pembelajaran bahasa Indonesia dimulai. Literasi membaca sendiri dalam PIRLS 2006 didefinisikan sebagai "the ability to understand and use those written language foems required by society and/or valued by the individual. Young reader cancoustruct meaming from a variety of texts. They read to learn, to participate in communites of readers in school and everyday life, and for enjoyment. Literasi dipahami sebagai " seperangkat kemampuan mengolah informasi, jauh di atas kemampuan, mengurai dan memahami bahan bacaan sekolah" (Pakistianingsih. 2014: 14- 16).

Dalam menciptakan budaya literasi membaca, pihak sekolah dapat membuat kegiatan seperti siswa diwajibkan memebawa buku bacaan berbahasa Indonesia kemudian siswa diperintahkan untuk membaca buku tersebut selama kurang lebih 15 menit sebelum guru memberikan materi pelajaran. Pihak sekolah bisa membuat kebijakan apakah kegiatan tersebut hanya dilakukan ketika mata pelajaran bahasa Indonesia saja atau dalam semua mata pelajaran. Kemudian guru meminta siswa untu membuat resensi buku tersebut sebagai bukti bahwa siswa tersebut sudah melakukan kegiatan literasi membaca.

Artinya adalah dengan adanya budaya literasi membaca ini diharapkan siswa dapat meningkatkan pemahamannya mengenai suatu bacaan. Selain itu dengan adanya kegiatan ini, siswa dapat menambah kosa kata baru dalam bahasa Indonesia sehingga bisa meningkatkan penggunaan bahasa Indonesia dalam kehidupan sehari-harinya. 


\section{SIMPULAN}

Bagi sebagian besar penutur bahasa Indonesia, bahasa daerah merupakan bahasa ibu atau bahasa pertama dalam kehidupan seharihari. Hal ini mengakibatkan pengaruh pada saat mereka menggunakan bahasa Indonesia. Pengaruh bahasa Jawa pada pembelajaran disebabkan oleh beberapa faktor. Diantaranya adalah pertama, mayoritas penggunaan bahasa daerah adalah dilingkungan pedesaan, disitulah bahasa daerah (bahasa Jawa) lebih dominan dibandingkan bahasa indonesia. Kedua, bahasa yang diperoleh siswa dari orangtua atau pengasuh sejak lahir adalah bahasa Jawa sehingga bahasa Jawa itulah yang menjadi bahasa ibu penutur tersebut. Sejalan dengan pernyataan tersebut dapat menyebabkan siswa menjadi terbiasa dalam penggunaan bahasa Jawa sehingga siswa akan mengalami kesulitan ketika diminta untuk berbahasa Indonesia yang baik.

\section{DAFTAR PUSTAKA}

Chaer, Abdul dan Leonie Agustina. 2004. Sosiolinguistik. Jakarta: Rineka Cipta.

Chaer, Abdul. 2003.Psikolinguistik-Kajian Teoritik. Jakarta: PT. Rineka Cipta. Kridalaksana, Harimurti.2001. Kamus Linguistik (Edisi Ketiga).Jakarta: Gramedia.

Hidayat, Rahmat dan Teguh Setiawan. "Interferensi Bahasa Jawa ke Dalam Bahasa Indonesia pada Keterampilan Berbicara Siswa Negeri 1 Pleret, Bantul". Jurnal Lingtera, 2 (2): 156168.

Kholidah, Umi. 2015. "Pemertahanan Bahasa Jawa pada Interaksi Siswa dan Guru dalam Pembelajaran Kajian Sosiolinguistik di MTS AL-Hikmah Pasir Demak”. Jurnal Ranah, 4 (2): 105114.

Linguistik.id. 2016. Pengertian Penelitian Deskriptif Kualitatif. https://www.linguistikid.com/2016/09/pengertianpenelitian-deskriptif- kualitatif.html. Diakses pada 12Februari-2019.

Mulyani, Wahyu. 2014. "Interferensi Leksikal Bentuk Dasar Bahasa Jawa Tuban dalam Bahasa Indonesia: Suatu Tinjauan Deskriptif'. Bastra, 1 (2): 113-140.

P.W.J. Nababan. 1989. Sosiolinguistik.Jakarta: PT. Gramedia Pustaka Utama Jakarta.

Pakistyanngsih, Arin. 2014. Surabaya Sebaga Kota Literasi. Surabaya: Kepala Badan Arsip dan Perpustakaan Kota Surabaya.

Rulyandi, Muhammad Rohmadi, dan Edy Tri Sulistyo. 2014. "Alih Kode dan Campur Kode dalam Pembelajaran Bahasa Indonesia di SMA". Jurnal Paedagogia, 17 (1): 27-39. 
Septiana, Dini rahma. 2014. Pengaruh Bahasa Daerah Terhadap Siswa $S D$.

Filsafat ilmu.

https://dinirahmaseptiana.blogspot.com/2014/12/pengaruhbahasa-daerah-terhadap.html?view=flipcard. Diakses pada 8-Februari 2019.

Triyanto, Hanif dan Endang Nurhayati. 2016. Interferensi Gramatikal Bahasa Jawa dalam Bahasa Indonesia pada Karangan Laporan Peserta didik SMP. Jurnal Lingtera, 3 (1): 23-36.

Wikipedia. Pengertian Lingua Franca. https://id.wikipedia.org/wiki/Lingua_franca. Diakses Pada 5-Februari- 2019.

Widianto, Eko. 2015. "Interferensi Bahasa Arab dan Bahasa Jawa pada Tuturan Masyarakat Pondok Pesantren Sebagai Gejala Pergeseran Bahasa".

Proseding International Seminar Jalan Imam Bardjo, S.H. No.5 SemarangMaster Program Linguistics Undip. 